\title{
DEVELOPMENT OF INTEGRATED INTELLIGENT CAD SYSTEM FOR DESIGN OF CYLINDRICAL HELICAL COMPRESSION VALVE SPRINGS
}

\author{
Adi Pandzic, Damir Hodzic \& Ismar Hajro
}
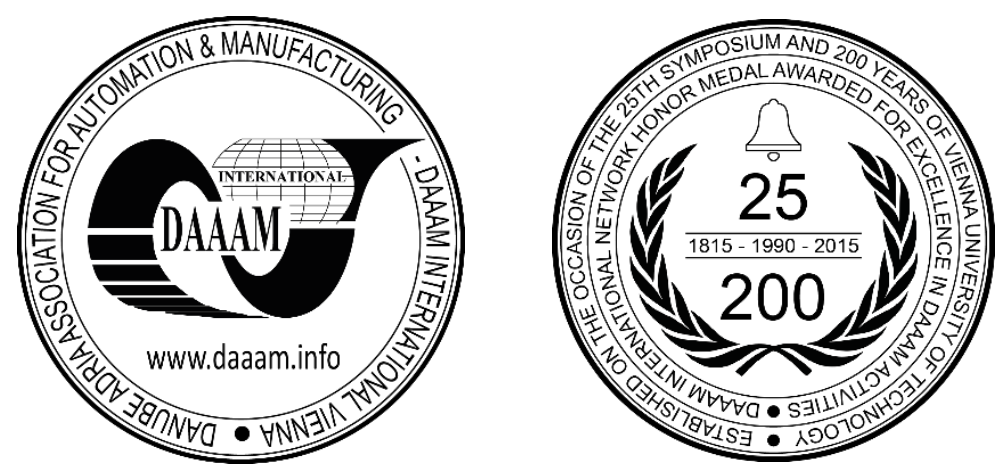

This Publication has to be referred as: Pandzic, A[di]; Hodzic, D[amir] \& Hajro, I[smar] (2018). Development of Integrated Intelligent CAD System for Design of Cylindrical Helical Compression Valve Springs, Proceedings of the 29th DAAAM International Symposium, pp.0665-0673, B. Katalinic (Ed.), Published by DAAAM International, ISBN 9783-902734-20-4, ISSN 1726-9679, Vienna, Austria DOI: $10.2507 / 29$ th.daaam.proceedings.096

\begin{abstract}
This paper presents architecture and process of developing an integrated intelligent CAD system (IICAD) for designing helical compression springs named SPRINGER. This paper presents steps and procedures to develop IICAD system for helical compression springs, but can be used for other specific types of products. The system is developed in C\# which is connected with Solidworks CAD system to save time during calculation and design of cylindrical helical compression valve springs (CHCV spring). After finishing calculation, SPRINGER system gives full report of calculation in PDF and 3D model of calculated spring in Solidworks that can be used for production, rapid prototyping, FEM analyse etc.
\end{abstract}

Keywords: IICAD; C\#; Solidworks; spring

\section{Introduction}

The development of innovative products and their realisation by means of advanced manufacturing methods and process combinations is a key issue in international competitiveness. Technological expediency, operational necessity and economic efficiency allowed wide spreading of industrial automation. The production system will work well, achieve growth and development only if it meets the conditions of the market, or if the products are usable, economical, designed with quality, environmentally friendly (ecological), competitive and acceptable for the market. The mutually opposing requirements have never been more prominent, since the product developing team must design and produce the product at the lowest cost, and at the same time have quality and other attributes that are maximally adapted to the changing demands and needs of customers [1], [2], [3].

The basic precondition that company should satisfy, in order to be successful, is to keep the existing market and possible expand it. In order to do this, it is necessary to meet the demands of the market for a longer period of time. At the same time, the market continuously raises more and more complex requirements regarding the quality and productivity of designing new products. The dominant influencing factors for the success of the company are: product quality, speed of product development and product innovation, cost-effectiveness in all segments of the company and presence in the international market [4], [5], [6]. 
As a consequence of stated, there is a need for: better quality scientific approach and better understanding of the construction-designing process, using a greater number of so-called construction tools that are software-based, interaction between these tools and better collaboration between constructors and designers [7].

Over time, product design has undergone many different phase changes, Figure 1. shows these phase changes [4], [5]:

- From manual design to automated design (CAD/CAM)

- From non-interactive design do interactive design

- From isolated, sequential design, to integrated, concurrent, and to co-operative/collaborative design

- From non-intelligent design, to intelligent design, to integrated intelligent design

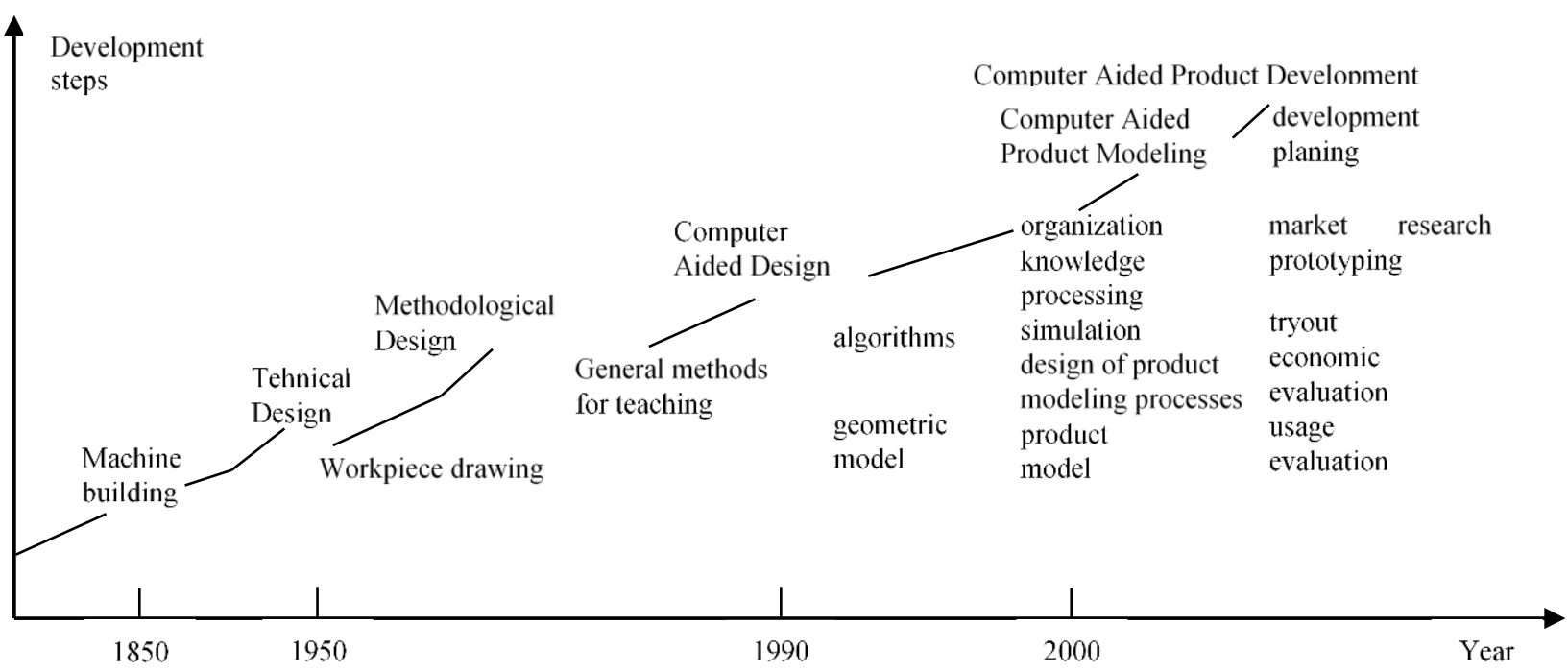

Fig. 1. Evolution of product development process [5]

The goal of this research is to present the architecture and development of one integrated intelligent CAD system for constructing and designing a specific type of product, specifically this article is about cylindrical helical compression valve spring. Through this research application Springer is developed, which has a task to perform the calculation of the CHCV springs, and to generate 3D model in software Solidworks, based on that calculation, which can be used later for various engineering purposes.

\section{Architecture of Springer IICAD system}

Springer IICAD system is .NET application written in C\# programming language. The system has been developed on modular principle and allows the user (designer, student and pupil), with the computer support, to perform certain construction design activities. The basic task of the system is to enable integrated application of developed modules / agents (expert knowledge-based systems) for the user, in order to accelerate and automate the certain activities in the process of construction and designing of $\mathrm{CHCV}$ springs [8], [9].

The architecture of Springer IICAD system is given in Figure 2. The Springer IICAD system is separated into several phases through which the user passes before reaching the final result:

- Choice of language (Bosnian or English)

- Defining working condition (mounting force, working force, spring working stroke, spring diameter)

- Set the safety factor (according to dynamic endurance)

- Selecting spring material characteristics (wire strength grade, minimal tensile strength)

- Cylindrical helical compression valve spring dimensions calculation

- Checking the level of safety factor according to dynamic endurance

- Checking the level of safety factor according to amplitude endurance

- Automatic generation of calculation report

- Automatic generation of 3D geometric model 


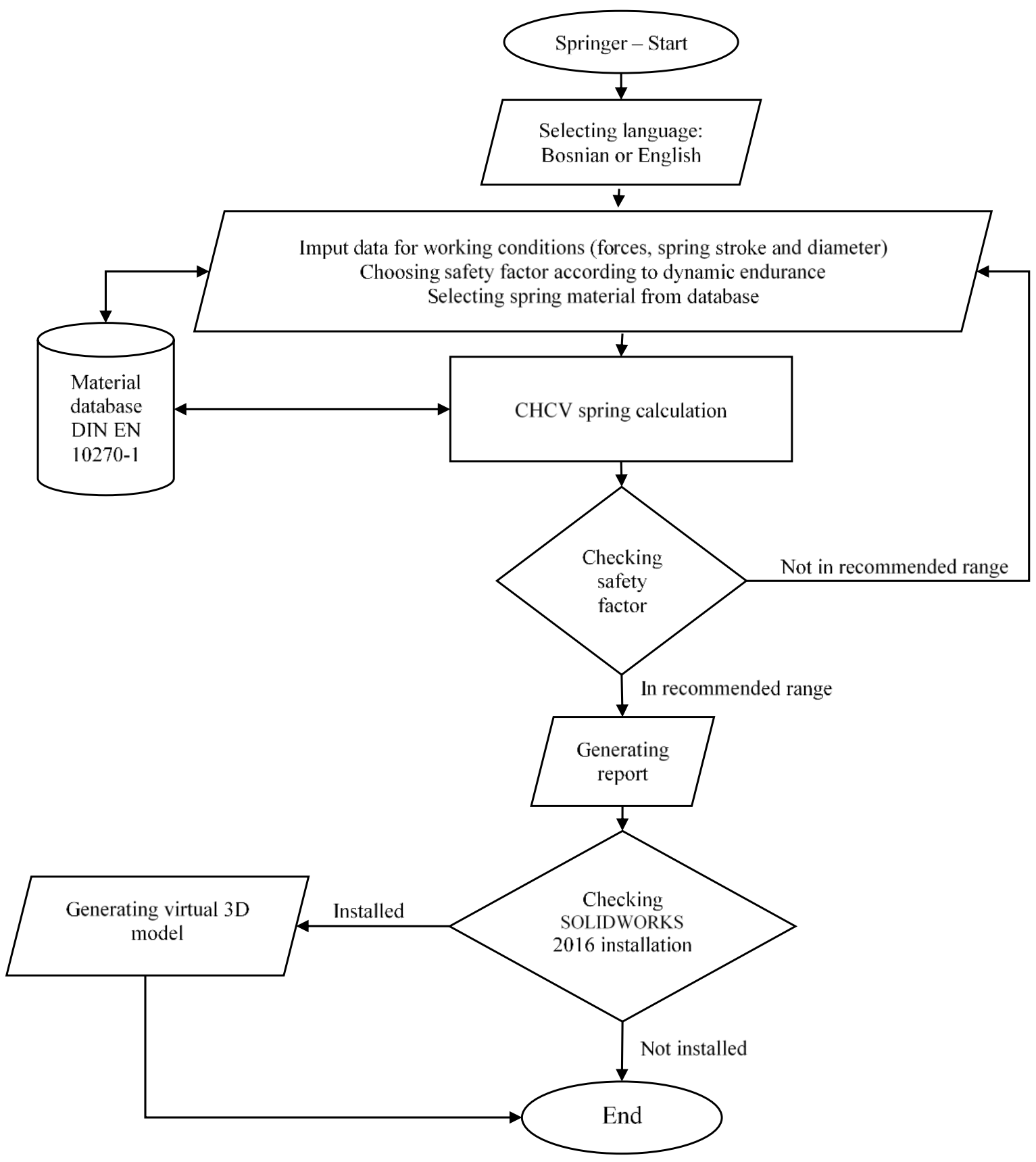

Fig. 2. Springer IICAD system architecture

Springer IICAD system is installed as any other windows-desktop applications, after installation application takes not more than $20 \mathrm{MB}$ of memory space of HDD (hard disk drive) computer.

One of the key activities in any product design process is to develop a geometric model of the product from the conceptual ideas, which can then be augmented with further engineering information pertaining to the application area. For example, the geometric model of a design may be developed to include material and manufacturing information that can later be used in computer-aided process planning and manufacturing (CAPP/CAM) activities. A geometric model is also a must for any engineering analysis, such as a finite element analysis (FEA) [10].

The main goal of this system is to obtain final 3D model of CHCV spring, so user can use that 3D model for production, creation of 3D element catalogue, mounting assemblies, real time rendering, rapid prototyping, movement simulation, FEM analysis, drafting of technical documentation and more.

After opening application, first thing that user have to do is to select the language, and this interface is shown in Figure 3. 


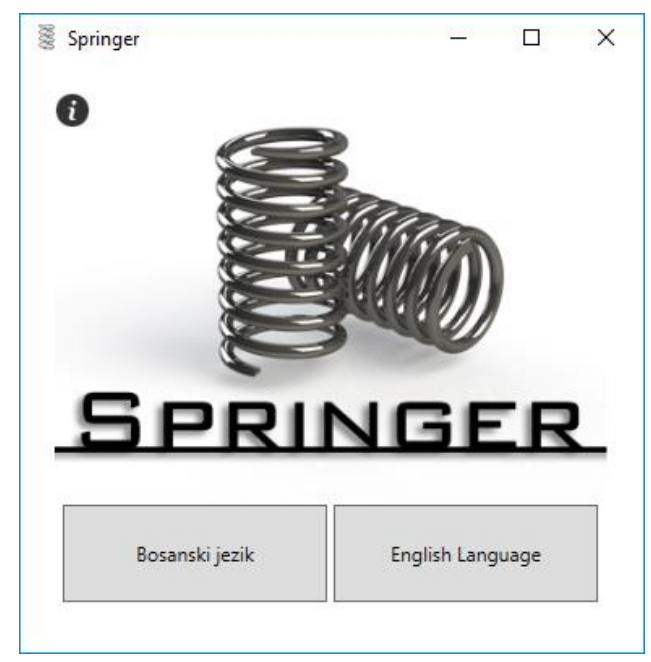

Fig. 3. Springer IICAD system interface - selecting language

As it's shown in Figure 3. Springer system is constructed on the principle of two languages: Bosnian and English. After choosing one of languages, user have to input required data as shown in Figure 4.

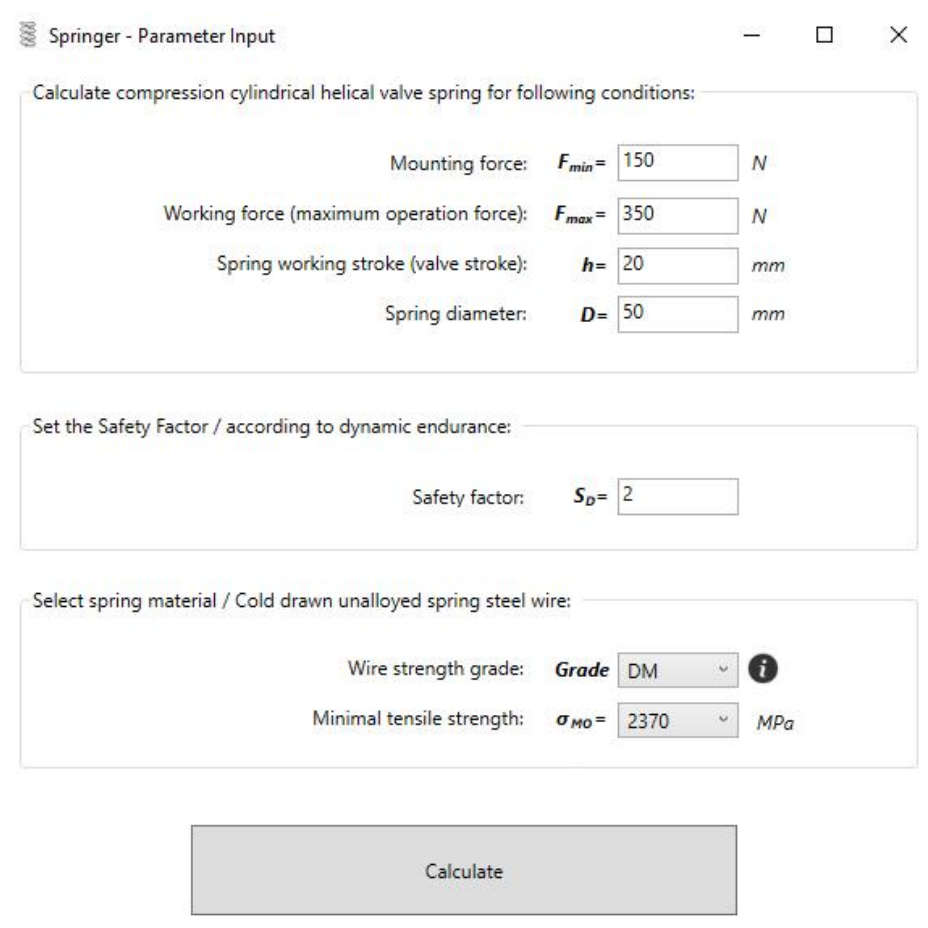

Fig. 4. Springer IICAD system input data interface

Also user have to set safety factor according to dynamic endurance, $S_{D}(\mathrm{~mm})$, and to select characteristics of spring material:

- Wire strength grade

- Minimal tensile strength

Material is cold drawn unalloyed spring steel wire according to DIN EN 10270-1:2001. After setting all input data, user can start calculation pressing the button "Calculate".

After calculation is finished, in new application window user gets CHCV spring dimensions and comment about level of safety factor according to dynamic and amplitude endurance, as shown in Figure 5. If level of safety factor is in recommended values range, user will get confirmation written in green colour. If it's not in recommended values range, the message will be written in red colour and user will be noted to edit material properties (pressing "Edit Parameters" button) or some other parameters. 

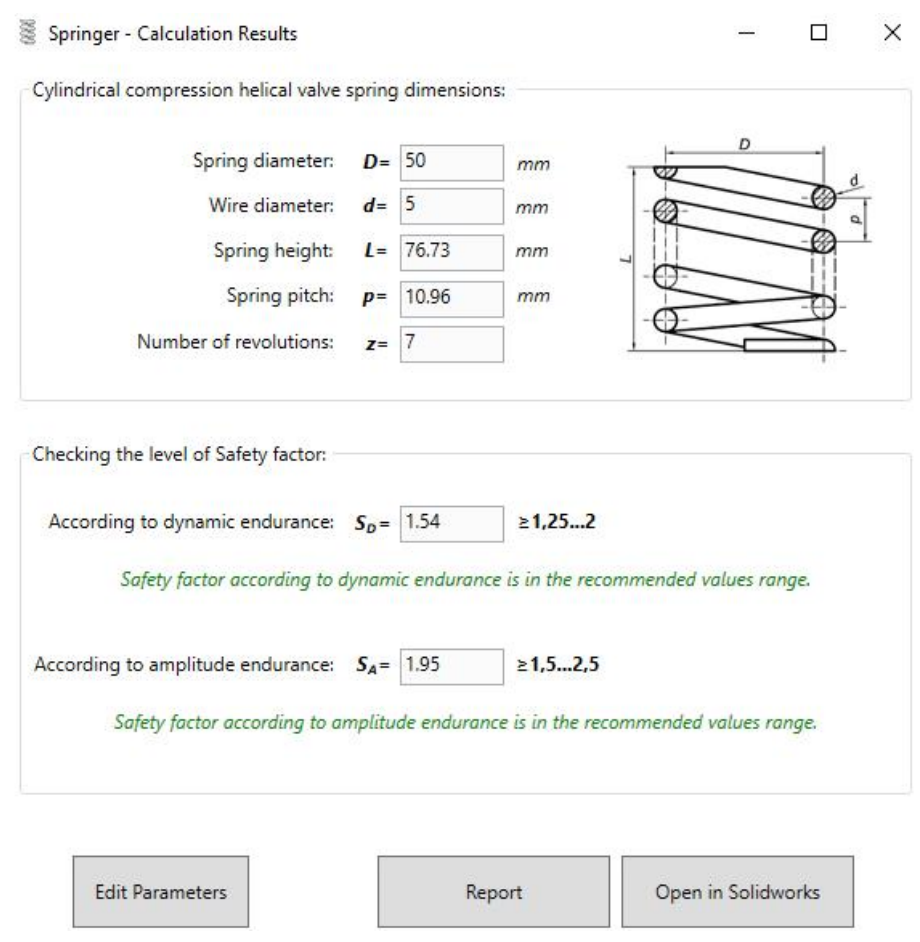

Fig. 5. Springer IICAD system results data interface

At the end, user can create 3D model of calculated CHCV spring in Solidworks, and also get full calculation report in pdf document.

\section{Mathematical model of $\mathrm{CHCV}$ spring}

Calculation of cylindrical helical compression valve springs shown in Fig. 6. can be done using procedure shown in [11]. This calculation procedure is implemented in Springer IICAD system. Calculation is based on input data:

- Mounting force (assembly condition force), $\mathrm{F}_{\min }(\mathrm{N})$

- Working force (maximum load force), $\mathrm{F}_{\max }(\mathrm{N})$

- Spring working stroke (valve stroke), $\mathrm{h}(\mathrm{mm})$

- Spring diameter, D (mm)

- Safety factor (according to dynamic endurance), $S_{d}$

- Spring material, wire strength grade and minimal tensile strength, $\sigma_{\mathrm{MO}}$

Springer IICAD system consist integrated material database, based on DIN EN 10270-1:2001 standard for cold drawn unalloyed spring steel wire, and allow user to select material characteristics like wire strength grade and minimal tensile strength.
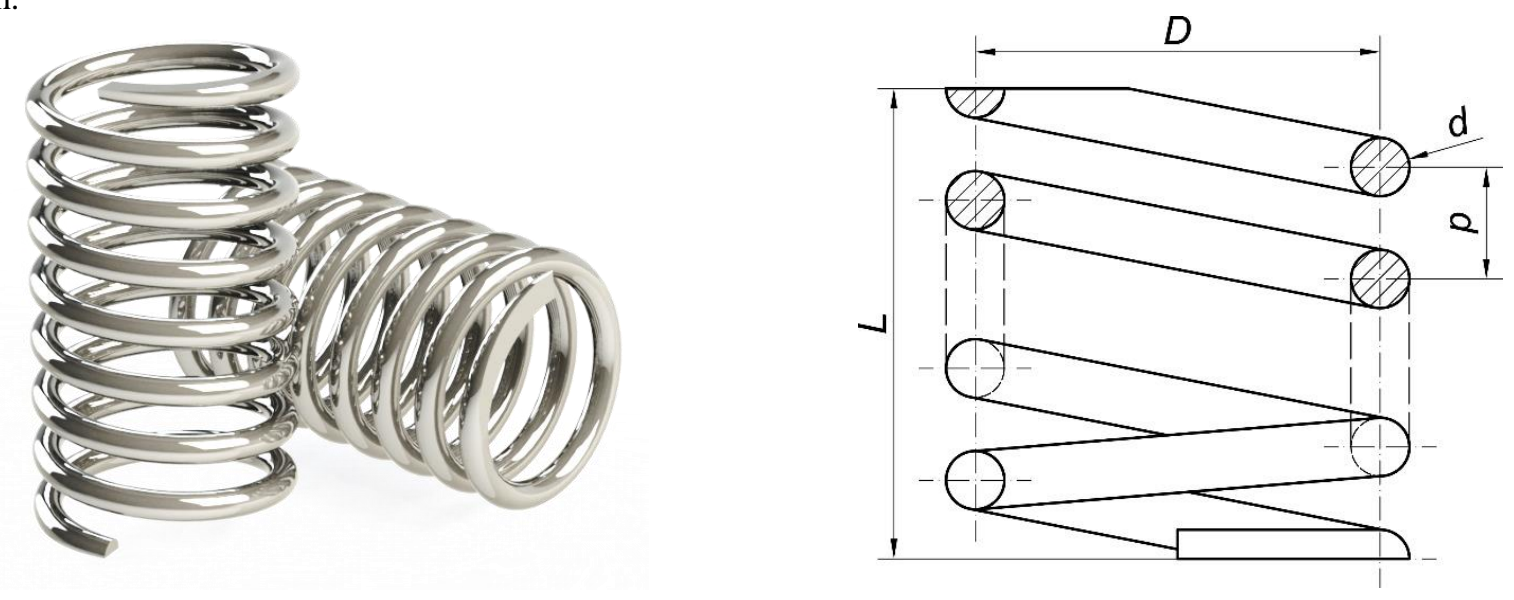

Fig. 6. Cylindrical helical compression valve springs 
Spring wire diameter d can be calculated by:

$$
d=\sqrt[3]{\frac{8 \cdot F_{\max } \cdot D \cdot S_{D}}{\pi \cdot \tau_{D o}}},(\mathrm{~mm})
$$

Where:

$\tau_{\text {Do }}(\mathrm{MPa})$ - spring dynamic endurance

After calculation, first approaching standard value of wire diameter is selected according to DIN EN 10270-1. Springer IICAD system also calculating data for the construction of modified Goodman diagram for selected spring material and checking the level of safety factor according to amplitude and dynamic endurance.

Total number of turns z (number of revolutions) can be calculated by:

$$
z=z_{a}+(1,5 \div 2)
$$

Where:

$\mathrm{z}_{\mathrm{a}}$ - number of active turns and can be calculated by:

$$
z_{a}=\frac{G \cdot d}{8 \cdot c \cdot K^{3}}
$$

Where:

G (MPa) - shear modulus according to EN 10270-1

$\mathrm{c}$ - spring stiffness, (4)

$$
c=\frac{F_{\max }-F_{\min }}{h},(\mathrm{~N} / \mathrm{mm})
$$

$\mathrm{K}$ - spring diameter and wire diameter ratio, (5)

$$
K=\frac{D}{d}
$$

Spring length in the free state L can be calculated by:

$$
L=L_{b l}+f_{\max }+S_{a},(\mathrm{~mm})
$$

Where:

$\mathrm{L}_{\mathrm{bl}}$ - spring length in the locked position, (7)

$$
L_{b l}=z \cdot d,(\mathrm{~mm})
$$

$\mathrm{f}_{\max }-$ spring deflection at maximum load, (8)

$$
f_{\max }=\frac{F_{\max }}{c},(\mathrm{~mm})
$$

$\mathrm{S}_{\mathrm{a}}(\mathrm{mm})$ - the sum of smallest gaps between helical turns of compression spring under load according to DIN 2095 / DIN EN 15800.

At the end spring pitch $\mathrm{p}$ can be calculated by:

$$
p=\frac{L}{z},(\mathrm{~mm})
$$

\section{Parametric 3D geometry model for Springer IICAD system}

Parametric modelling is well developed technology to utilize previous design to develop new design by varying parameters. Parametric modelling has made product development phase quick and efficient. Parametric 3D model can be designed in many CAD softwares like Solidworks, Inventor, Catia V5 and more. For Springer IICAD system 3D model, we used Solidworks CAD software to generate parametric 3D model. Solidworks is a 3D design software developed by Dassault Systèmes. The complete design platform contains: 3D design software, analysis software and product data management software. This tool makes it possible for mechanical designers to quickly sketch ideas, experiment with features and dimensions, and produce models and detailed drawings. [12], [13], [14]. 
CHCV spring is designed as one part with command "Helix and Spiral", for 3D sketch of helix (Figure 7. left). The first step is to create circle sketch, and that circle sketch will be used to generate helix 3D sketch. Diameter of this circle in first sketch is spring diameter. After we create helix, using feature command "Swept Boss/Base" and setting "Circular Profile" we can generate 3D model of spring (Figure 7. right).
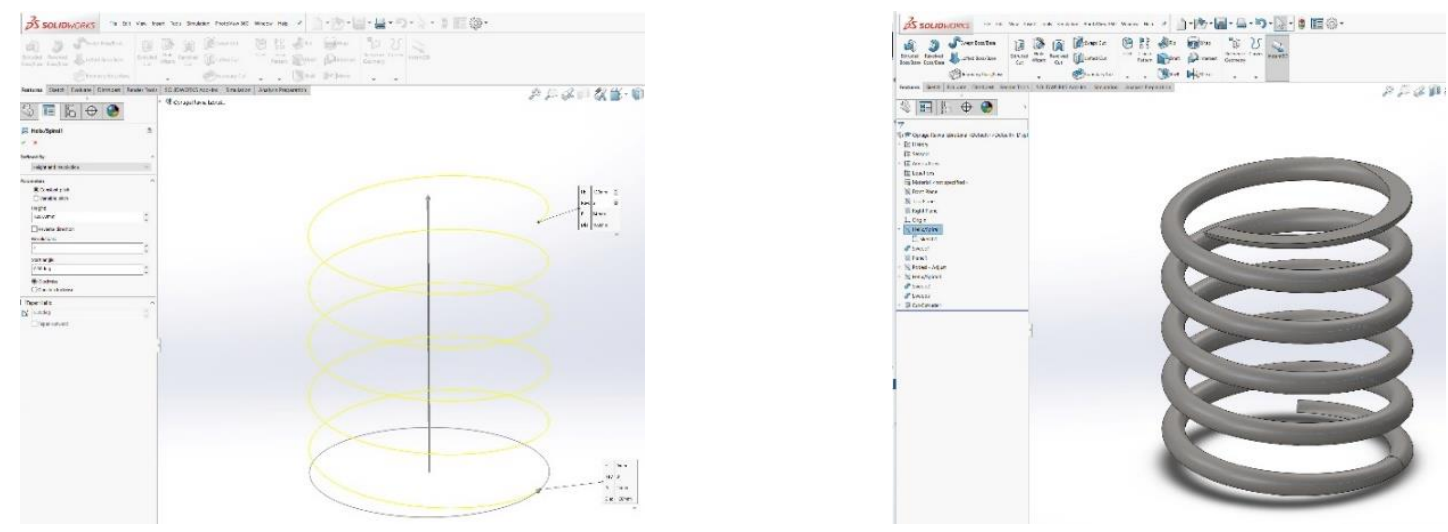

Fig. 7. Helix sketch and 3D model of spring in Solidworks

Springer IICAD system allow us to choose spring end types before generating 3D model in Solidworks, and user can select "Open and ground" or "Closed and ground". To create grounded spring, we used feature command in Solidworks called "Extruded Cut" and for this feature we have to create one more sketch (Figure 8.).

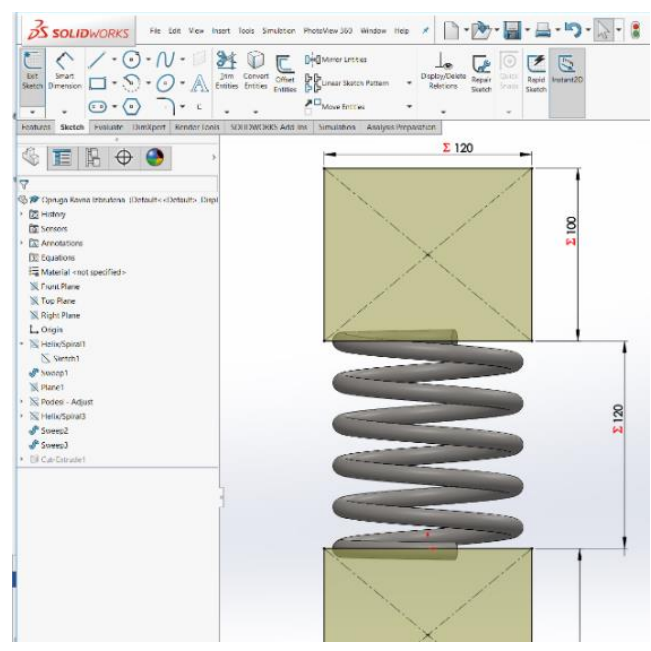

Fig. 8. Creating sketch for making open and closed ground type spring

After creating 3D model, it is necessary perform parameterization of 3D model that could be connected to Springer IICAD system. In this step with commands "Insert" - "Tables"- "Design Table" design table is created and dimensions and parameters from sketches and features of 3D model are connected with Excel table (Figure 9).

\begin{tabular}{|c|c|c|c|c|c|c|c|c|c|c|}
\hline \multirow{2}{*}{$\frac{1}{1}$} & A & B & C & D & $E$ & $\mathrm{~F}$ & G & $\mathrm{H}$ & 1 & $\mathrm{~J}$ \\
\hline & Design T & Spring diameter & & Number of turns & & Spring height & Wire diameter & & & \\
\hline 2 & & 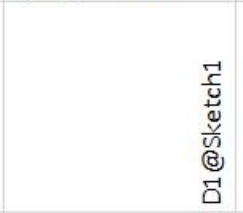 & 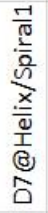 & 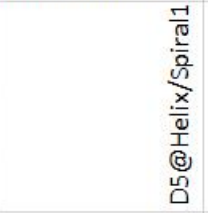 & 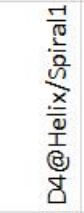 & 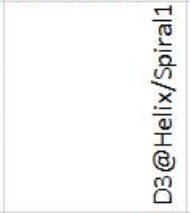 & 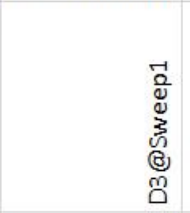 & $\begin{array}{l}\text { or } \\
\text { Oे } \\
0 \\
\text { w }\end{array}$ & $\begin{array}{l}z \\
\text { ㅁ } \\
\text { 点 } \\
\text { 品 } \\
\text { 岁 } \\
\text { 足 }\end{array}$ & \\
\hline 3 & Default & 100 & 0 & 5 & 24 & 120 & 10 & 12370374 & Default & \\
\hline
\end{tabular}

Fig. 9. Design table with 3D model parameters created in Solidworks

Also relations between dimensions and parameters on 3D model of spring are created in Solidworks with "Equations" (Figure 10.) 


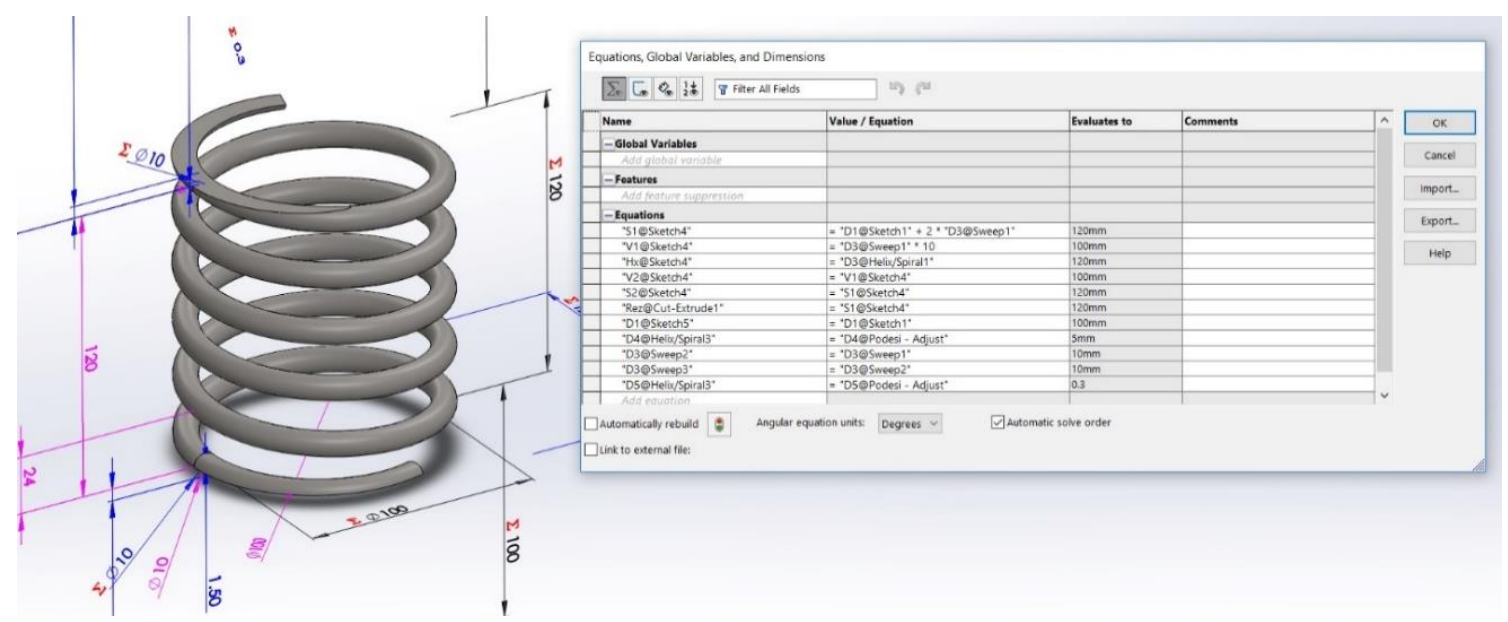

Fig. 10. Equations of spring 3D model in Solidworks

After creating 3D model of spring, setting relations between dimensions and parameters using equations in Solidworks, result is creating design table which can be saved like Excel table and connected with IICAD system.

\section{Experimental testing of Springer IICAD system}

IICAD system provides strong support for the RP (rapid prototyping) and CNC (computer numerical control) technology. A good designer, with appropriate hardware and IICAD system, can quickly realize the conceptual design of the product and deliver it to the purchaser for verification [7]. After performed research, with the aim to additionally test and verify practical application, Springer IICAD system is tested with Ultimaker $2+3 \mathrm{D}$ printer to create 3D printed CHCV spring after all calculations in Springer. Ultimaker $2+$ is one of the best FFF (fused filament fabrication) desktop printer, that uses a continuous filament of a thermoplastic material. First step is to set input data in Springer, then finish calculations and generate 3D model. From Solidworks we have to convert 3D model to STL (an abbreviation of "stereolithography") format because this format of 3D model is used for 3D printing.

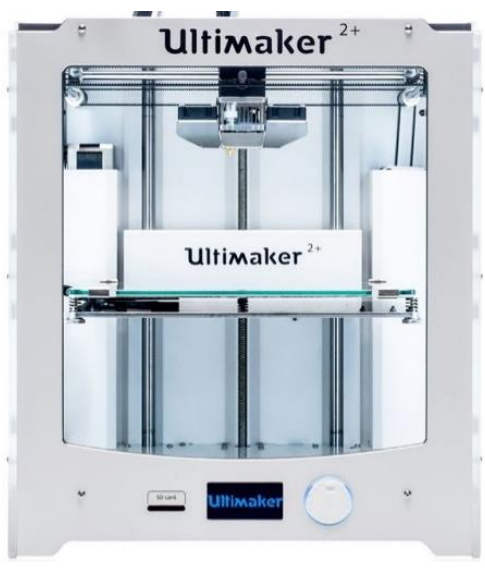

1.
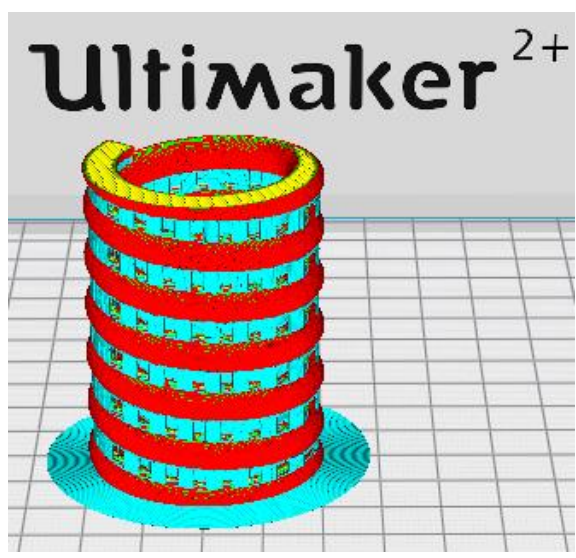

2.

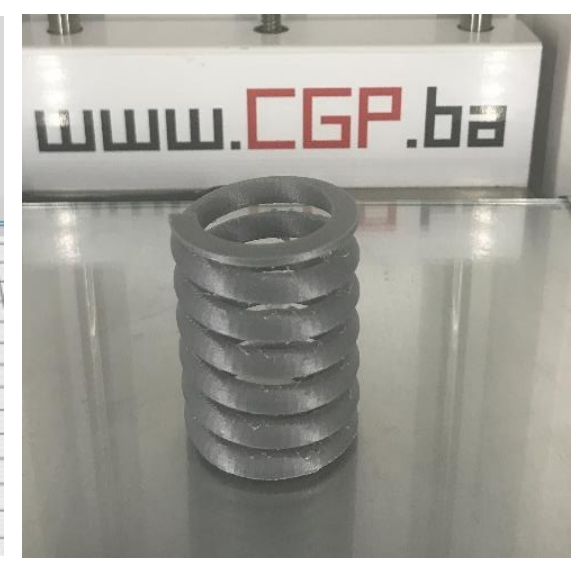

3.

Fig. 11. Ultimaker 2+ 3D printer (1.), 3D model of spring in Cura software (2.) and 3D printed CHCV spring (3.)

Spring 3D model in STL format is prepared for 3D printing in Ultimakers software Cura. In this software 3D print parameters can be adjusted and G-code can be saved on memory card and transferred to 3D printer. After all, CHCV spring 3D model form Springer IICAD system was 3D printed (Figure 12.). Ultimaker 2+ allows to use different materials for 3D printing, for this research PLA material was used.

\section{Conclusion}

Product design process is a complex process, where team of many engineers and designers working together to solve problems and find best solution for product and company to be competitive. To be competitive company need to develop a product with better quality and price than their competition. Engineers and designers, in process of developing new product, need to take care in consideration all necessary aspects (technical, technology, functional, materials, economical, ergonomic, market analysis and productivity) and to do many iterations trough developing a new product. 
Most of companies still use classical conventional methods for product design which is sequential and non-intelligent approach. Today focus is on how to increase the level of automation of design and manufacturing process and to create more "intelligent" system which will save time and help in developing a new product. One of solutions is development of intelligent integrated CAD systems like IICAD system presented in this paper, with the goal to present procedures and steps to develop IICAD system for specific type of product. This review paper present aspects of developing and implementation of an integrated intelligent CAD system. Detailed steps are presented how to develop one IICAD system for designing of cylindrical helical compression valve spring, but idea can be implemented for design of any other product.

Based on research analysis results and verification of practical application of the developed Springer IICAD system or IICAD system in general, it may be concluded as follows:

- Springer IICAD system can help engineers and designers during calculation and design of CHCV springs

- Shorter time of development and designing process (more than 50\% compared to conventional system application, depending on product complexity)

- Better product quality

- Lower design process cost (up to $90 \%$ compared to conational designing, depending on product complexity and applied resources)

- Company becomes more competitive with its products on domestic and international market.

- Enables quick calculations of design parameters

- Enable automatic generation of 3D model and making changes easy

From the above it is reasonable to say that it is justified to invest in the development of the IICAD systems and it is expected that in the future IICAD systems will be combined with artificial intelligence which will greatly contribute and change the way of product development.

\section{References}

[1] Lukić, D.; Milošević, M. \& Todić, V. (2013). Integrated CAPP Systems and Technology Database, University of Novi Sad, Faculty of Technical Science, Novi Sad

[2] Yerofeyev, S. A.; Ipatov, O. S.; Markov, S. A.; Potekhin, V. V.; Sulerova, A. S. \& Shkodyrev V. P. (2016). Adaptive Intelligent Manufacturing Control Systems. 26t DAAAM International Symposium on Intelligent Manufacturing and Automation, DAAAM International, (2016) page numbers (1016-1024), 1726-9679

[3] Dubovska, R.; Jambor, J. \& Majerik, J. (2013). Implementation of CAD/CAM system CATIA V5 in Simulation of CNC Machining Process. 24t DAAAM International Symposium on Intelligent Manufacturing and Automation, Procedia Engineering 69, (2014) page numbers (638-645), 1877-7058

[4] Šarić, I. (2014). Development of Integrated CAD System for Design of Mechanical Power Transmissions, Ph.D. Dissertation, Department of Mechanical Design, University of Sarajevo, Sarajevo, Bosnia and Herzegovina

[5] Xuan, F. Z. (2005). Artificial intelligence and integrated intelligent systems in product design and development, Nanyang Technological University and Institute of Manufacturing Technology, 978-1-58603-675-1, Singapore

[6] Šarić, I.; Muminović, A. (2018). Development of Integrated Intelligent CAD system for synthesis and stressdeformation analysis of pressure vessels. International Journal of Engineering \& Technology, Vol 7., No 3.9., (May 2018) page numbers (147-151), 2227-524X

[7] Šarić, I.; Pervan, N.; Muminović, A. \& Čolić, M. (2018). Development of Integrated Intelligent CAD System for Design of Shafts. Tehnički Vjesnik, Vol. 21, No. 1, (June 2018) page numbers (99-104), 1330-3651

[8] Šarić, I.; Muminović, A.; Čolić, M. \& Rahimić, S. (2017). Development of Integrated Intelligent Computer-Aided Design System for Mechanical Power-Transmitting Mechanism Design, Available from: https://doi.org/10.1177/1687814017710389 Accessed: 2018-07-18

[9] Ćatić, A. (2011). Knowledge-based Engineerin in Product Development Processes - Process, IT and Knowledge Management Perspectives, Ph.D. Dissertation, Department of Industrial and Material Science, Chalmers University of Technology, Gothenburg, Sweden

[10] Xun, X. (2009). Integrated Advanced Computer-Aided Design, Manufacturing, and Numerical Control, Information Science Reference (an imprint of IGI Global), ISBN 978-1-59904-714-0, USA

[11] Repčić, N. \& Muminović, A. (2007). Mechanical Elements II, University of Sarajevo, Faculty of Mechanical Engineering Sarajevo, Sarajevo

[12] Wawre, S. S. \& Kabade, D. K. (2016). An Overview of Recent Trends in Parametric Modeling. International Journal of Modern Trends in Engineering and Research, Vol. 03, No. 4, (April 2016) page numbers (381-389), 2349-9745

[13] Pomazan, V.; Sintea, S.; Bordea, N. \& Bordea, V. (2012). Solution for Real Time Design Data Transport for the CAD Parametric Features. Anals of DAAAM for 2012 \& Proceedings of the $23^{\text {rd }}$ International DAAAM Symposium, Vol. 23, No. 1, (2012) page numbers (879-882), 2304-1382

[14] Popa, C. L.; Parpala, R. C. \& Cotet, C. E. (2012). Contact Identification for Assembly/Disassembly Process in CADCAE Software. Anals of DAAAM for 2012 \& Proceedings of the $23^{\text {rd }}$ International DAAAM Symposium, Vol. 23, No. 1, (2012) page numbers (613-616), 2304-1382 